\title{
The Early Childhood and Comprehensiveness
}

\author{
Irena Alimerko \\ PhD Candidate at European University of Tirana, Albania
}

\section{Doi:10.5901/mjss.2014.v5n27p474}

\begin{abstract}
The preschool children with typical development who interact with children with special needs demonstrate behaviors with a high understanding, empathy and tolerance for individual differences. There must consider attentively some premises to better understand the concept of comprehensiveness of preschool children. Children with special needs who participate in comprehensive environments are less involved in social relations comparing to their peers with typical development. The preschool children with special needs have a higher risk of rejection by their peers with typical development. That's why is necessary to use the effective intervention strategies. The comprehensive classes allow and enable more social acceptance by all children. The most common barrier of comprehensive education is the lack of adequate support for both, teachers and students. There are identified three problems related to this issue: The first problem is related to the behavior of such children that are perceived as a reason for distraction of the others. A second problem is the lack of the specialized assistance in education classes. Many teachers of the general education do not have adequate knowledge to teach effectively the pupils with special needs. The third problem is related to the financial costs. Such details as additional educational assistants, educational facilities, transportation and staff development would require an additional financial costs. While there are many benefits, there are also many challenges. One of the biggest challenges is the change of the attitude of teachers. The success of the comprehensiveness depends on the involvement of all actors. Although there is too much to be done in order to ensure that all children benefit from the comprehensiveness, there are already some accomplishments that provide convenient education for all children.
\end{abstract}

\section{Introduction}

The comprehensive education is one of the best forms of education for all children. It is the right of every child to be educated in school and to be treated with dignity. Teaching must be adapted to the specific needs and opportunities of children. School is the place of education for every child regardless their abilities ${ }^{1}$.

The comprehensiveness of the preschool children with the special needs in the learning environments with peers with typical development is a contemporary phenomenon that has started since 1990. This movement is supported by data that show that $50 \%$ of preschool children with special needs are served with facilities comprehensive learning. Children with special needs are guaranteed the education within the public education system and this type of education is useful to help them to reach the potential of learning, but this should be given within the current school and not in an isolated way.

According to legal perspectives the comprehensive education is considered as a political strategy based on human rights and democratic principles that confront all forms of discrimination, as a sign of developing an inclusive society where such children are not ignored or neglected. The most important issue of the comprehensive education is that allows children with special needs to stay with their families and to go to the nearest kindergarten, alike all other children. After the official signing of the International Convention on the Rights of the Child the reaction has been positive toward the rights of children with disabilities. In the law "For pre-university education" is clearly defined the obligation of the state for the education of children with disabilities.

From a moral and philosophical perspective is supposed that children with special needs should not be separated from peers with typical development because the segregation itself is anti-ethical to human rights. In the Convention of United Nations on the Rights of Children is emphasized the right of children with disabilities to be educated as all other children in accordance with their mental and physical capacity. Likewise, one of the objectives of the National Strategy for People with Disabilities is: "To provide access to education for all children with disabilities, giving priority to comprehensive education". ${ }^{2}$ When preschool children with special needs participate actively in comprehensive learning

\footnotetext{
${ }^{1}$ World Vision, The Right of Children with Disabilities in Comprehensive Education. Tiranë, March 2012, p. 4.

2 World Vision, The Right of Children with Disabilities in Comprehensive Education. Tiranë, March 2012, p, 3-4. 
environments, they develop behaviors that increase their initiatives in social situations, complex linguistic skills and / or communication, increase the opportunities for generalizing skills and decrease inappropriate behaviors. The education of preschool children with special needs together with the children with typical development bring benefits also to the latter.

The preschool children with typical development who interact with children with special needs demonstrate behaviors with a high understanding, empathy and tolerance for individual differences. There must consider attentively some premises to better understand the concept of comprehensiveness of preschool children. Children with special needs who participate in comprehensive environments are less involved in social relations comparing to their peers with typical development. The preschool children with special needs have a higher risk of rejection by their peers with typical development. That's why is necessary to use the effective intervention strategies.

\section{Overview}

When a preschool child with special needs is accepted in a comprehensive environment, the educational personnel, first must determine the level of social competence and integration of the child and then determine realistic objectives, expectations and learning opportunities. The comprehensiveness during preschool period is supported from the social competence. The fact is that preschool children with a typical development don't have negative connotation reducing so the chances of rejection and mockery towards children with special needs. If the experiences of preschool children with typical development in a comprehensive environment are positive, these experiences will encourage the development of positive attitudes towards disabled people during the preschool years and ongoing.

Conversely, negative experiences in comprehensive environments of learning during the preschool years can affect on the prejudices against children with special needs. The education systems are oriented to serve to preschool children with slight disabilities excluding those with heavy disabilities. The level of development of a child with special needs can play a significant role in the process of social interaction with the peers with a typical development. Preschool children with e typical development have more social relations with their peers with slight special needs than with the less able peers. The issue we are bringing out here isn't about the realization of the comprehensiveness, but how the professionals can compose and implement programmes in order to increase its effectiveness.

\section{The Factors that Affect the Successful Comprehensiveness}

There are many factors that affect the success of comprehensiveness. Besides the family, school is for a child the first model of an organized society. If we do not include them today in the communities of our schools, tomorrow will be very late for these children to be part of our social community. This is an undeniable right of every human being. ${ }^{3}$ The negative attitudes of the teachers may vary in positive ones if these factors are considering properly. Most of the teachers aren't able and they feel unprepared to fully support such programmes. That's why it is necessary the opportunity of professional development through different trainings and activities such as: observations in other classes, analyses and searches on the process of comprehensiveness as well as the cooperation with other colleagues in order to develop a successful programme for comprehensiveness. If the teachers are supported with the necessary training, they will begin to feel more relaxed in working with disabled children and implementing different programmes of their comprehensiveness.

The success of comprehensiveness is also affected from the attitudes of the teachers and directors. They have an important role, whether in school or kindergarten. The collaboration between the teachers of the special education and those of the general education is another factor that affects the success of the process. They can develop together a strategy of learning and intervention that will help in promoting the success of all children in general education. It is also helpful if they will be trained together so that they can share ideas and learn how to work together effectively in order to teach the pupils in general education.

\section{Barriers to Comprehensiveness}

There are identified three problems related to this issue:

1- The first problem is related to the behavior of such children that are perceived as a reason for distraction of the others.

3 The Albanian Foundation for the Rights of People with Disabilities, The Albanian School Toward the Integrated Process, Tiran ë, 2002, p. 33-34. 
2- A second problem is the lack of the specialized assistance in education classes. Many teachers of the general education do not have adequate knowledge to teach effectively the pupils with special needs.

3- The third problem is related to the financial costs. Such details as additional educational assistants, educational facilities, transportation and staff development would require an additional financial costs.

One of the biggest challenges is the change of the attitude of teachers. The success of the comprehensiveness depends on the involvement of all actors.

While there are many challenges, there are also many benefits from the education of comprehensiveness. The full comprehensiveness may not be appropriate for all children, but it offers a range of benefits for children, teachers, parents and whole society. One of the greatest benefits is the academic program of all children in kindergarten and school. Disabled children are more concentrated in learning and interact easily with their peers when they are included in regular classes.

Also disabled children have more positive role models from which they can learn when they are engaged with peers without disabilities. However, the teachers and parents of children in general education are concerned by considering that this process would hamper the progress of the academic programme of their children. But, referred to a study conducted by Cole, Waldron, and Maljd (quoted in Peck, Staub \& Gallucci, 2004) children without disabilities that have been registered in the comprehensive classes have had highest achievements than those registered in traditional classes.

Another benefit from the process of comprehensiveness is the social acceptance and interaction among peers. Disabled children establish strong friendships with peers without disabilities, when they participate and learn together in the same classes. They accept easily the differences between each other that will affect in less violence and discrimination towards children with disabilities. The comprehensive classes allow and enable more social acceptance by all children. The most common barrier of comprehensive education is the lack of adequate support for both, teachers and students.

Although there is too much to be done in order to ensure that all children benefit from the comprehensiveness, there are already some accomplishments that provide convenient education for all children.

\section{Methodology}

For the realization of this study we have been based on qualitative method through which we have extracted data on this specific group. While this is a sensitive topic because affects on the personal behavior, considering the interaction aspect of the subject, we have been attentive in the way of approaching our modalities with the subject of our searching. Certainly, there have been used the most productive mechanisms of this method, based on observation, semi-structured interviews with adults, involving teachers and parents, as well as personal stories, which are not brought here in details for confidentiality reasons. These stories have served only to reinforce the results of this paper.

\section{Results}

As a result of a good approach of comprehensiveness,

1- the preschool children with special needs manifest appropriate behavior that increases their initiatives in social situations, complex linguistic skill and / or communication and decreases inappropriate behavior in interaction with the others.

2- This process affects positively also to children with typical development. When these children interact with children with special needs they demonstrate such behavior with a higher understanding, empathy and tolerance for individual differences.

\section{Conclusions}

The public education system is useful to help the children with special needs to reach the potential of learning, but this should be given within the current school and not in an isolated way. The most important issue of the comprehensive education is that allows children with special needs to stay with their families and to go to the nearest kindergarten, alike all other children. If the experiences of preschool children with typical development in a comprehensive environment are positive, these experiences will encourage the development of positive attitudes towards disabled people during the preschool years and ongoing. Conversely, negative experiences in comprehensive environments of learning during the preschool years can affect on the prejudices against children with special needs. 
Disabled children are more concentrated in learning and interact easily with their peers when they are included in regular classes. Also disabled children have more positive role models from which they can learn when they are engaged with peers without disabilities. Disabled children establish strong friendships with peers without disabilities, when they participate and learn together in the same classes. They accept easily the differences between each other that will affect in less violence and discrimination towards children with disabilities.

Most of the teachers aren't able and they feel unprepared to fully support such programmes. That's why it is necessary the opportunity of professional development through different trainings and activities such as: observations in other classes, analyses and searches on the process of comprehensiveness as well as the cooperation with other colleagues in order to develop a successful programme for comprehensiveness. If the teachers are supported with the necessary training, they will begin to feel more relaxed in working with disabled children and implementing different programmes of their comprehensiveness.

The collaboration between the teachers of the special education and those of the general education is another factor that affects the success of the process. They can develop together a strategy of learning and intervention that will help in promoting the success of all children in general education

Besides the family, school is for a child the first model of an organized society. If we do not include them today in the communities of our schools, tomorrow will be very late for these children to be part of our social community. This is an undeniable right of every human being.

\section{References}

The Albanian Foundation for the Rights of People with Disabilities, The Albanian School Toward the Integrated Process, Tiran ë, 2002 World Vision, The Right of Children with Disabilities in Comprehensive Education. Tiranë, March 2012 